\title{
Effects of Integrating E-Media Piano in Teaching Music
}

\author{
Teejay D. Panganiban ${ }^{1}$, John Gabriel G. Contreras ${ }^{1}$, Kenneth D. Malabanan ${ }^{1} \&$ Jen Patrice A. Sayas $^{1}$ \\ ${ }^{1}$ College of Teacher Education, Batangas State University JPLPC-Malvar, Batangas, Philippines \\ Correspondence: Teejay D. Panganiban, College of Teacher Education, Batangas State University JPLPC-Malvar, \\ Batangas, Philippines.
}

Received: November 29, 2018; Accepted: December 19, 2018; Published: December 31, 2018

\begin{abstract}
Historically, schools, universities and adult education providers have used a "lecture-based" teaching model. This approach to learning was developed during the industrial age, some two centuries ago. The concept is for students to sit passively in rows of chairs or tables all facing the presenter, who usually resides at a lectern. A lecture is a "one-to-many" form of communication, involving little or no audience participation. It is authoritarian, by nature. For an information dump a lecture works fine. The development of engaging lecture activities requires a significant amount of instructor preparation and limits the time available to provide traditional lectures. However, the positive results of this study suggest the need for a restructuring of the plain classroom lecture to incorporate more engaging lectures to improve both the qualitative experiences and performance levels of students.

Due to the fast changing society and modernization, there is also change in interest of the students learning styles, so the researchers conducted a study about the effect of educational software in teaching music.

This research determined the effects of integrating e-media piano in teaching music at Santiago National High School. Specifically, it dealt with the following: the pretest result of the control and experimental group, the posttest of the two groups; and the significant difference between the pretest and posttest results of the two groups.

The input of the study was determined by administering the researcher-made test which is the principal tool for gathering the needed data. The gathered data underwent statistical treatments such as mean, standard deviation, $\mathrm{t}$ test for independent means and t-test for dependent means.

A pretest was administered from the two study groups before the conduct of the experiment; this is to determine if the groups were equally comparable in terms of intellectual ability. The validated and reliability teacher-made test is composed of twenty-five (25) items. This covered topics about the different elements of music such as melody, tempo, dynamics, rhythm, pitch, harmony, texture, and timbre. Moreover, both groups were given posttest after the experimental period had been conducted. The same 25 multiple choice item tests was given to the experimental and control group to find out if the use of E- Media piano software had an effect to the students' performance in music. Nevertheless, the latter was superior than the former. Thus, the effectiveness of E-media is notable, enhancing the learners' capacity for acquisition and retention of information.

The integration of e-media piano software to traditional classroom instruction may be encouraged. Educational software specifically designed to fit the learning objectives can be used as motivation, enrichment activity, and as an assessment tool to classroom instruction. The active participation and interest that educational software may provide to the teaching and learning process should be exploited. Educational software made and developed appropriately to the level of the learners may be adopted not only in music but in the other components of M.A.P.E.H as well. Other strategies which may integrate other trends articulated with the interest of today's learners may also be adapted as exposing students to modernized school can achieve a quality education and can produce lifelong learning.
\end{abstract}

Keywords: effects, integrating, electronic media piano

\section{Introduction}

Technology has increasingly become an integrated part of people's lives especially in education. Thus, it gives life and meaning to everything and fills the inadequacy of knowledge in individuals. With this reason, technology became the most popular and frequently used tools in every sector especially in education. Technology has changed aspects of people's daily lives, it is undoubtedly changing education. Since technology nowadays arrived, educational technology exists and it can be a beneficial resource inside the classroom. 
Educational technology is used to aid in visual representation that can also be teaching tools with the help of interactive media. This kind of media can display software programs which enables the learner to acquire knowledge in simplest way. Simple software or applications can add more interest in students learning process. Software and applications can be a good medium of instruction to motivate learners. This software can also be categorized as software for music which learning may be in the form of multimedia, CD-ROMs that are installed on a computer, networkable software, downloaded software, or programs that are on the web for free. This software is specifically either instruction or drill in notation and aural skills, music creativity software, or music perception games.

Software programs in music grow gradually so it is hard for the strategic management to deliver efficient software applications that is in higher demand to the public. Seeing this issue on moderate process of giving software throughout the world, the National Association of Music Merchants (NAMM) conducted a global report about the statistical result of producing software in music. In year 2014, NAMM made a research about the twenty one countries including Argentina, Australia, Austria, Brazil, Canada, China, Finland, Germany, India, Italy, Japan, Mexico, Norway, Russia, South Korea, Spain, Sweden, Switzerland and, of course, the United States. In addition, the Czech Republic makes its first appearance in the report, and the United Kingdom returns after taking a few years off. These twenty one countries made a great impact in music industries like software programs in music being exported and imported throughout the world. In England, the Department for Education and the Department for Media recognize the importance of music in the lives of young people and to ensure that they consistently give this people a music education with the highest quality. In United States, there are technology classes composed of 47 percent for music technology and 37 percent for music education technology. The First International Music Technology Conference in Southeast Asia held in Kuala Lumpur recently received lukewarm response in terms of turnout and contributions.

However, the under developing counties like the Philippines, music technology has to offer seem cumbe _. . $\quad$ In addition, The Philippine Society for Music Education (PSME) conducted seminars and workshops in music with the integration of technology. These seminars are said to be open on every teachers help to develop pedagogical skills in music among participants. The purpose of this seminar is to have advancement pedagogy in music education. It seeks to provide directions towards creative and effective music instruction in the pre-school, elementary and secondary levels. This is in response to the growing awareness and needs of classroom music teachers for know-how on the basics of music education research methodology. They want to unlock the difficulties in the context of issues in Philippine Music Education by raising the level of consciousness on the role of music as imperative in the aesthetic development of the Filipino, in the formation, preservation and transmission of cultural heritage and in the development of nationhood, by upgrading the standards of music instruction through continuing music education training programs, workshops and seminars for classroom teachers, and by coordinating with government and private educational institutions and provide assistance in the formulation of policies in music education and in recommending standards to be achieved in the various levels of classroom music instruction.

According to Roblyer (2014) Educational Technology is seen as a systematic approach to designing, improving, and delivering instruction matched to the carefully identified needs. Baume and Fleming (2006) proposed new modes of learning for the $21^{\text {st }}$ century learners. The modal preferences are comparatively difficult for a student to change or for an educational system to respond.

According to Morrison (2016) the attention of preferring learning modes allows flexibility for students and teachers to modify their behaviors. One of these learning modes is the Visual Learning or modality. Since the students nowadays are mostly visual learners, some educational software will be a great tool in terms of delivering instructions. In addition to this, Edgar Dale's Cone of Experience stated that direct purposeful can make a foundation of learning into a concrete or first-hand experience. Thus, students will develop constructing ideas through the use of senses.

Students find music as a hard one especially in performing different instruments because of the lack of experience on it. According to the Music Parents Guide (2015), there exist four major reasons why the students have difficulties in learning. First, the student is not musically talented or atleast the pedagogical ways are not enough. Secondly, the student is too busy with other activities more likely downloaded games then they hates practicing just because of the instinct that they can't play it. Lastly the students doesn't like their teachers way of teaching.

There comes a complete transformation of learning music to which technology maybe utilized. Most likely to happen, teachers commonly use charts, visual pictures, printed materials, books, etc. in teaching their lessons. In addition to this there are no enough facilities like instruments, videos and other technology or non- technology 
aided materials. According to Free Patent Online (2006), in the study of Alverez (2006), a total of 228 teachers responded to the survey for a percentage of $31 \%$. Of the 228 responses, $50 \%$ reported that they "strongly agreed" that they lacked sufficient school supplies, materials and resources in order to do their jobs properly. An additional $40 \%$ "agreed" that they too lacked sufficient supplies, materials and resources. No teacher surveyed claimed that they did have adequate supplies, $6 \%$ were "neutral" and $4 \%$ had no response. In addition to that, according to the National Center for Education Statistics, most public school teachers about $84 \%$ are reported having at least one computer in their classrooms, which is very low. $36 \%$ of teachers had one computer in their classrooms, $38 \%$ reported having two to five computers in their classrooms, and $10 \%$ reported having more than five computers in their classrooms. Teachers and students with more computers or computers connected to the Internet in their classrooms generally used these technologies more often than teachers with fewer computers or Internet connections. Also, computer and Internet availability was not equally distributed among schools. Teachers in schools with the lower minority enrollments composed of less than $6 \%$ to $20 \%$ were more likely to have the Internet and software available in the classroom than teachers in schools with the highest minority enrollments which composed of $50 \%$ or more minority enrollments about $69 \%$ and $71 \%$ compared with $51 \%$. Moreover, teachers in schools with the lowest minority enrollments less than $6 \%$ were more likely to report having two to five computers connected to the Internet than teachers in schools with the highest minority enrollments about $19 \%$ compared with $9 \%$. To change this underlying situation, music educators need to be more proficient in integrating technology as their medium of instruction. Since the students nowadays are engaging their life in technology, music educators must think of more interactive yet knowledgeable one. Teachers must bring the students into the process of learning they want.

Since, students nowadays have cellphone or tablets; teachers may utilize downloading software and use this as the medium of instruction. They must not only consider technology itself, but also curricular outcomes, pedagogy, and the teaching learning context when designing learning experiences for students. It is important for music educators to consider the ramifications of new and developing technologies on creating, performing, listening, and learning aboutmusic. Through current and emerging technologies, people of all ages and from all walks of life may be able to engage in meaningful musical experiences throughout their lives.

Aside from entertainment and first-hand experiential purpose, software may also serve as a medium for knowledge transmission. This transmitting knowledge varies according to two socio-factors. These factors may affect the students learning difficulties.

Firstly, is the behavior of the learner towards learning. Thus, Accuosti (2014) said that teacher had to manage not only classroom control, but also the ethical implications of technology and the moral hazards. Those hazards include not only plagiarism and threats, but also external circumstances which took students' attention away from the plans they created involving the technology. Teachers must be concerned about customizing technology for students of migrant status, economic status, disabilities and their perceived attitudes about social responsibility. Students must develop intellectually and morally. Those types of challenges cannot be solved with classroom technology. Socio-factors can derive from within ICT or come from external forces; they affect the technologyuse and ultimately, the lesson at stake.

Secondly, is the student's environment exposure. When the students grew with instrument in their houses or even they saw people using it, they become more curious about it. According to the Science Daily (2014), the more curious people are about a topic, the easier it is to learn information about the topic. Gruber (2014) said that curiosity provides insights into what happens in our brains when is piqued and these findings suggest ways to enhance learning in the classroom and other settings.

The researchers from the Bachelor of Secondary Education, who are majoring in MAPEH, conducted a study on the effects of integrating e- media piano in teaching music at Santiago National High School. The researchers believe that it would be best to conduct the research among the grade nine students because they are the batch that undergone Instrumental Music of the Romantic Period. According to DepEd Curriculum Guide in Music (2013), this content includes lessons about piano music and its musical elements. DepEd also involves in their learning competency the integration of piano in different musical elements; the batch undergoing the innovation of curriculum and at the same are among $21^{\text {st }}$ century visual literacy life-long learners.

This study benefitted the researchers for the result of their study might be a basis for their future career as educator, since they knew the effect of integrating technology in music as an instruction for teaching. The researchers can apply it also when they are in field of teaching. 


\subsection{Objectives of the Study}

This part provides the context for the research study and generates the questions which the research aims to answer. This study determined the effects of integrating e-media piano in teaching music at Santiago National High School. Specifically, this study sought answers to the following questions: What is the pretest result of the experimental and control groups? What is the posttest result of the experimental and control groups? Is there a significant difference in the performance of the two groups in: Pretest; and Posttest? And last question, What is the implication of the findings of the study to the teaching of Music in Grade 9?

\section{Methodology}

This present study employed the experimental method of research. According to Ardales (2008), if the aim of the researcher is to find out what caused the change or effect that has been made, the said method is best to use. In this approach the researcher intentionally and systematically controls and manipulates certain stimuli, treatments and conditions, and observes how the condition or the behavior of the subject is affected or changed. The abovementioned measures were executed by the researchers in gathering data needed in the course of the present study.

The experimental method was used to introduce some basic features of causal reasoning that turned out to be useful. The researchers deemed this method appropriate because its nature of dealing with cause and effect coincides with the aim of the present undertaking which is determining causal connections of integrating e-media piano in teaching music to the respondents. The experimental group was given a certain stimuli, then the behavior of the respondents was observed - whether it changed or not.

For the purpose of interpreting the level of performance in the pre-test and post-test of the control group and experimental group, the mean scores were grouped and given the following interpretation:

\begin{tabular}{lll}
\hline Score Ranges & Mean Range & Verbal Interpretation \\
\hline $21-25$ & $20.00-25.00$ & Excellent \\
$15-20$ & $15.00-19.99$ & Very Satisfactory \\
$11-15$ & $10.00-14.99$ & Satisfactory \\
$6-10$ & $5.00-9.99^{\circ}$ & Fair \\
$0-5$ & $0.00-4.99$ & Poor \\
\hline
\end{tabular}

\section{Results and Discussion}

This chapter presents the analysis and interpretation of data gathered. The data are presented in textual and tabular form organized in a sequential manner, which resembled the order of presentation of specific problems posed in Chapter I.

\subsection{Pretest Results of the Control and Experimental Groups}

A pretest was administered to the two study groups before the conduct of the experiment; this is to determine if the groups were equally comparable in terms of intellectual ability. The validated and reliability tested teachermade test is composed of twenty-five (25) items. This covered topics about the different elements of music such as, melody, tempo, dynamics, rhythm, pitch, harmony, texture, and timbre.

Table 1 below shows the pretest results of the experimental and control groups. It depicts the mean scores of the respondents with their corresponding verbal interpretation. The mean scores of the respondents were grouped and categorized as follows: $20.00-25.00$ as excellent, $15.00-19.99$ as very satisfactory, $10.00-14.99$ as satisfactory, and 5.00-9.99 as fair and $0.00-4.99$ as poor.

Table 1. Pretest Results of the Experimental and Control Group

\begin{tabular}{lll}
\hline Study Groups & Mean & Verbal Interpretation \\
\hline Experimental Group & 12.00 & Satisfactory \\
Control Group & 12.10 & Satisfactory \\
\hline
\end{tabular}

The pretest mean score of the experimental group was 12.00 while the mean score of the control group was 12.10 . Both were interpreted as satisfactory.

This finding is parallel to the study of Macaraig et al. (2006) which studied the effect of computer education to the music class of St. Louis Anne College. It showed that control and experimental groups attained almost the same 
level of performance before the intervention regarding their skills in Music, noting further that the two study groups are equally comparable as confirmed by a little difference between their pretest mean scores.

Table 2. Posttest Results of the Experimental and Control Groups

\begin{tabular}{lll}
\hline Study Groups & Mean & Verbal Interpretation \\
\hline Experimental Group & 18.40 & Very Satisfactory \\
Control Group & 15.90 & Very Satisfactory \\
\hline
\end{tabular}

The posttest mean score of the experimental group is 18.40 interpreted as very satisfactory. In the other hand, the control group obtained a mean score of 15.90 which was classified as satisfactory. Integrating E-media piano software in class discussion were innovations on the traditional method of teaching.

The result of the present study was supported by the findings of Mario (2007) used who musical instrument digital interface (MIDI) accompaniment and computer-assisted instruction (CAI. It happened that in group piano, students' performance accuracy and attitudes resulted to the positive involvement of musical instrument using CAI and improve in pitch accuracy during the early stages of learning new repertoire. The study concluded that students changed their attitudes towards learning the elements of music in new way and students learn easily while having fun listening to the discussion. This was revealed by the huge difference in the posttest results of the two groups. Thus, the students exposed to E- Media piano software performed better that the students exposed to the traditional method of teaching.

Table 3. Summary of the Pretest and Posttest Results of the Experimental and Control Groups

\begin{tabular}{lll}
\hline Study Groups & Pre-test & Post-test \\
\hline Experimental Group & 12.00 & 18.40 \\
Control Group & 12.10 & 15.90 \\
\hline
\end{tabular}

Table 3 shows the summary of the pretest and posttest of the experimental and control groups. As shown in the table, the experimental group got the mean scores of 12.00 in the pretest and 18.40 in the posttest. It has a mean difference of 6.40. However, the mean scores of the control group in their pretest and posttest is 12.10 in the pretest and 15.90 in the posttest. It has a mean difference of 3.80. Since the mean difference of the experimental group is higher than that of the control group, this implies that there is an improvement in the test scores of the students from the experimental group. This may be due to the integration of E-Media Piano software in the class discussion of the experimental group

The results of the present study were parallel to that of Nicolls (2010). Both studies utilized computer based technologies that may help increase the performance of the students in terms of piano especially in the different elements of music. There was a huge increase in the posttest result of the students in the experimental group as well as the control group.

\section{Comparison of the Pretest Result of the Control and Experimental Groups}

\begin{tabular}{|c|c|c|c|c|c|c|}
\hline Study Groups & Mean & SD & Computed t-value & Tabular t-value & $\begin{array}{l}\text { Decision } \\
\text { (Ho) }\end{array}$ & Interpretation \\
\hline $\begin{array}{l}\text { Experimental Group } \\
\text { Control Group }\end{array}$ & $\begin{array}{l}12.00 \\
12.10\end{array}$ & $\begin{array}{l}1.76 \\
0.99\end{array}$ & 0.160 & 2.101 & Accept & Not Significant \\
\hline
\end{tabular}

$\mathrm{df}=18, \mathrm{a}=0.05$

The pretest mean scores of the experimental and control groups were compared using the t-test of independent means to determine their significant difference. The computed t-value was 0.160 . This was less than the tabular tvalue 2.101 with the degree of freedom of 18 at 0.05 level of significance. This made the researchers accept the null hypothesis that there is no significant difference in the pretest mean scores between the experimental and control group. 
Table 5. Comparison of the Posttest Result of the Control and Experimental Group

\begin{tabular}{lllllll}
\hline Study Groups & Mean & SD & Computed t-value & Tabular t-value & $\begin{array}{l}\text { Decision } \\
\text { (Ho) }\end{array}$ & Interpretation \\
\hline Experimental Group & 18.40 & 2.27 & & & & Significant \\
Control Group & 15.90 & 1.85 & 2.700 & 2.101 & Reject & ( \\
\hline
\end{tabular}

$\mathrm{df}=18, \mathrm{a}=0.05$

Table 5 showed that the experimental group had a mean score of 18.40 with a standard deviation of 2.27. However, the control group had a mean score of 15.90 with a standard deviation of 1.85 . This was supported by the findings of Argelio (2011) which found out that there was a significant difference in the posttest results of the experimental and control group. Thus, the null hypothesis was disconfirmed. The result of their study proved that Computer Aided Instruction can serve as a very good tool, an innovative, beneficial and effective approach in teaching science.

This was also parallel to the study of Nicolls (2010). She found out that developing the structure of the piano to better suit contemporary techniques and the addition of technological elements in piano playing by using software can enhance students learning abilities..

\section{Implication of the Findings of the Study to MAPEH Instruction}

The improvement of classroom instruction has always been a concern of educators worldwide. School institutions are aiming for a quality education. To achieve quality education they need to consider factors that will contribute to the changing needs of every school institution. Some factors to be consider are approaches, methods, strategies, and technique of teachers and the instructional materials they are going to use. Therefore this study found out that transforming the old pedagogy by using new and improved instructional materials in teaching can create better achievement in the learning outcomes of students.

With that, the result of the study implied that the use of E-Media piano in teaching music was more effective than the traditional method of teaching. Aside from charts, books, and traditional visual aids, teachers can download educational software and integrate it in their field of teaching. Instead of writing new music or composed songs in a piece of paper, students can used e-media piano as a recorder for every song they made.

Students learn faster in a medium that captivates their interest. Learning using educational software especially EMedia piano enhances students' interest in music instruction as they enjoy playing assessment activities in listening and thinking skills. Students learn easily and comprehend complex concepts by using e-media software.

In listening discussion, students can use their modernized software or application inserted in their mobiles. In relation to that, students are even more attentive listener and innovative creator in the field of music, because considering audio and visual aids at the same time will change student's attitude towards learning. So, this study had proven the positive effect of integrating e-media piano in teaching music before and after the learning process. The result also implies that the use of e-media software in motivating students is very effective and activity based material can add more energy in the minds of every students. The use of e-media during the class discussion can add joy and relaxation while participating actively in the class discussion. In terms of assessing students learning, e-media piano is also helps the teachers in giving more interactive yet knowledgeable quizzes through listening skills and mental skills.

With this finding, the integration of e-media piano software to traditional classroom instruction may be encouraged. Educational software specifically designed to fit the learning objectives can be used as motivation, enrichment activity, and as an assessment tool to classroom instruction. The active participation and interest that educational software may provide to the teaching and learning process should be exploited. Educational software made and developed appropriately to the level of the learners may be adopted not only in music but in the other components of M.A.P.E.H as well. Other strategies which may integrate other trends articulated with the interest of today's learners may also be adapted. As exposing students to modernized school can achieve a quality education and can produce lifelong learners.

\section{Conclusions and Recommendations}

Based on the findings of the study, the following conclusions were drawn: The control Group and experimental group performed satisfactorily in the pretest. The experimental group performed very satisfactorily while the control group performed satisfactory. There is no significant difference in the pretest scores between the two groups but there is a significant difference in the posttest of the two groups. The integration of E-media piano in 
the instruction of music is more effective than the plain lecture method which uses traditional instructional materials.

In the light of the findings and conclusions, the following recommendations are suggested:

Teachers may integrate E- media piano in their music lessons to increase students' participation and performance in the teaching learning process. School principals and MAPEH coordinators may encourage their teachers to use E- media piano software as an art of teaching music. School administration may allot budget for educational institution to support this kind of educational software. Music instructors may prepare materials and constantly expose music major students in integrating educational software such as E-media.

Lastly, similar studies may be conducted to further verify the result of this study. This may be done in other schools with a different set of subjects and with other areas of specialization.

\section{References}

Argelio, M. A., Dedios, S. I, \& Francisco, C. B. (2011). The effect of Computer Aided Instruction to the Performance in Biology of Second Year Students at Don Julio Leviste Vocational High School. Unpublished Thesis, Batangas State University-JPLPC, Malvar Campus, Malvar, Batangas.

DepEd. (2013). Curriculum Guide in Music. Retrieved from http://www.deped.gov.ph/sites/default/files/Music\%20Curriculum\%20Guide\%20Grades\%20110\%20December\%202013.pdf . DepEd Complex, Meralco Avenue, Pasig City

Free Patent Online. (2006). Retrieved from http://www.freepatentsonline.com

Gruber M. J (2014). States of Curiosity Modulate Hippocampus-Dependent http://www.deped.gov.ph/sites/default/files/Music\%20Curriculum\%20Guide\%20Grades\%20110\%20December\%202013.pdf Learning via the Dopaminergic Circuit. Cell Press.

Macaraig, F. K. C., \& Cabrera, M. A. S. (2006). The effect of computer education to the music class of St. Louis Anne College. Unpublished Thesis, Batangas State University-JPLPC, Malvar Campus, Malvar, Batangas.

Morisson, M. (2016). Dale- Cone of Experience. Rapidby. Wordpress Website by the BBS Agency.

Music Parents Guide. (2015). A Survival Kit for the New Music Parent. Genesis Framework, Wordpress.

Roblyer, M. D. (2014). Integrating educational technology into teaching. Upper Saddle River, New Jersey: Pearson Education, Inc..

\section{Copyrights}

Copyright for this article is retained by the author(s), with first publication rights granted to the journal.

This is an open-access article distributed under the terms and conditions of the Creative Commons Attribution license (http://creativecommons.org/licenses/by/4.0/). 